\title{
Longitudinal Study of Childhood Adiposity and the Risk of Developing Components of Metabolic Syndrome-The Da Qing Children Cohort Study
}

YAN-YAN CHEN, YUNG-SENG LEE, JIN-PING WANG, YA-YUN JIANG, HUI LI, YA-LI AN, YING-HUA HU, KOK O. LEE, AND GUANG-WEI LI

\begin{abstract}
Endocrinology and Cardiovascular Disease Center [Y.-Y.C., Y.-L.A.], Fuwai Hospital and Cardiovascular Institute, Chinese Academy of Medical Sciences and Peking Union Medical College, Beijing 100037, China; Department of Cardiology [J.-P.W., Y.-Y.J., H.L., Y.-H.H.], Da Qing First Hospital, Da Qing 163316, China; Departments of Pediatrics [Y.-S.L.] and Medicine [K.O.L.], Yong Loo Lin School of Medicine, National University of Singapore 119074, Singapore; Department of Endocrinology [G.-W.L.], China-Japan Friendship
\end{abstract} Hospital, Beijing 100029, China

\begin{abstract}
Childhood adiposity is increasingly recognized as a significant predictor of cardiometabolic risks in later life. The aim of this study was to investigate factors associated with longitudinal changes in weight during childhood and the development of metabolic disease risk factors. Four hundred twenty-four children from DaQing city, China, were recruited at $5 \mathrm{y}$ old and followed up for $5 \mathrm{y}$. Birth weight, television (TV) viewing time at $5 \mathrm{y}$ old, blood pressure, anthropometric measurements, fasting plasma insulin (FI), and triglycerides (TG) levels were measured at 5 and $10 \mathrm{y}$ old. Both birth weight and TV viewing time at $5 \mathrm{y}$ old significantly correlated with percentage of ideal weight for height (WFH) at $5 \mathrm{y}$ old (WFH5; $p=$ 0.0032 and $p=0.01$ ), but only TV time was significantly correlated with WFH at 10 y old (WFH10; $p<0.0001$ ). Blood pressures, FI, homeostasis model assessment for insulin resistance (HOMA-IR), and TG at $10 \mathrm{y}$ old were significantly greater in those children who had greater change in WFH from 5 to $10 \mathrm{y}$ old $(\Delta \mathrm{WFH})$. We concluded that TV viewing time was the stronger determinant of later childhood adiposity. A greater $\triangle \mathrm{WFH}$ was associated with increased cardiometabolic risk factors at 10 y old. (Pediatr Res 70: 307-312, 2011)
\end{abstract}

$\mathrm{C}$ hildhood obesity is becoming an increasing concern around the world and is already a major public health problem in China (1). Obese children often become obese adults (2), and obese children have a greater risk of developing hypertension, dyslipidemia, and impaired glucose tolerance or type 2 diabetes $(3,4)$. Childhood adiposity has a significant bearing on subsequent adult health and disease, and a higher BMI in childhood is associated with adult-onset diabetes $(5,6)$, hypertension $(7,8)$, visceral and s.c. fat mass $(9)$, metabolic syndrome (10), and coronary heart disease (11). Similarly, elevated fasting plasma insulin (FI) level in childhood is associated with the adult metabolic syndrome $(10,12)$.

A number of factors can lead to obesity in children, including genetic, behavioral, and environmental factors. In addition, childhood adiposity may be influenced by early life events like in utero fetal growth (13), breast feeding (14), and

Received November 8, 2010; accepted March 10, 2011.

Correspondence: Guang Wei Li, M.D., Department of Endocrinology, China-Japan Friendship Hospital, Ying Hua Road, Chao Yang District, Beijing 100029, China; e-mail: guangwei_li@medmail.com.cn

Supported by grant 98-1-080 from the Scientific Research Foundation of Ministry of Health of China. rapidity of weight gain during infancy $(13,15)$. A heavier birth weight has been shown to confer a higher risk of being overweight during childhood and adolescence $(16,17)$. Evidence from prospective observational studies suggests that increased physical activity and decreased sedentary behavior may be protective against weight gain in childhood and adolescence (18). Television (TV) viewing is a prevalent sedentary activity, and an estimated 26.5 to $49.2 \%$ of children 11 to $15 \mathrm{y}$ old watch TV for $4 \mathrm{~h}$ or more per day (19). TV viewing time has been consistently linked with a higher risk of being overweight in children and adults (20-23). The National Health Examination Survey examined 6671 children aged 12 to $17 \mathrm{y}$ and found the prevalence of obesity increased by $2 \%$ for each additional hour of TV viewed (20). Another study of 746 children 10 to $15 \mathrm{y}$ old reported 4.6 times greater risk of being overweight for youths watching more than $5 \mathrm{~h}$ of TV per day compared with those watching 0 to $2 \mathrm{~h}$ (21). There are relatively few studies which have examined the effect of TV viewing time on early growth in young $(<10$ y old $)$ Asian Chinese children.

Childhood adiposity and insulin resistance may have important implications on subsequent health outcomes. However, the longitudinal changes in adiposity during childhood may be the early metabolic changes which form the nidus for development of subsequent metabolic and cardiovascular disorders in later life. Our study examines the effects of TV viewing time and birth weight on the change in adiposity from 5 to 10 y old, as well as the impact on insulin sensitivity during the 5-y period. We also study the effects of change in adiposity in this period of late childhood on the development of metabolic disease risk factors. As far as we are aware, this is the first such study in a large Asian Chinese pediatric population.

Abbreviations: DBP, diastolic blood pressure; FI, fasting plasma insulin; HOMA-IR, homeostasis model assessment for insulin resistance; SBP, systolic blood pressure; TG, triglycerides; TV, television; WFH, percentage of ideal weight for height; WFH5, WFH at 5 years old; WFH10, WFH at 10 years old; $\mathbf{D W F H , ~ W F H ~ f r o m ~} 5$ to 10 years old 


\section{METHODS}

Subjects. Four public elementary schools in Da Qing city, China, were selected for this study. Children who were enrolling into first grade at these schools at their sixth year of life were all invited to participate in this study. Of the 605 children recruited for the study in 1998, 424 children (211 boys and 213 girls) were available for follow-up assessment 5 y later, and only the 424 subjects with complete data collected at both $5 \mathrm{y}$ and $10 \mathrm{y}$ old were analyzed for this study. Informed consent was obtained from the parents of the study participants, and the study was approved by the Ethics Committee of the China-Japan Friendship Hospital, Bureau of Education of Da Qing city, and the participating schools.

Birth weight and TV watching time. Birth weights of the subjects were obtained from birth certificates. Other data were provided by the subject's accompanying parent who completed a questionnaire at school on the previous $4 \mathrm{wk}$. Parents provided information on the number of hours per day their child watched TV for each day of the week (to nearest half an hour) and the number of days the child watched TV for that week.

Anthropometric measurements. All measurements were made by trained nurses when the children were first enrolled at $5 \mathrm{y}$ of age, and the same team made the measurements 5 y later. Participants wore light clothing and took off their shoes. Height was measured to the nearest $0.1 \mathrm{~cm}$ by a calibrated wall-mounted stadiometer. Weight was measured to nearest $0.1 \mathrm{~kg}$ with an electronic scale. The mean of the three recordings was used. As a BMI chart and z-scores for local children were not available, the percentage of ideal weight for height (WFH) was obtained for each subject for our analysis using our percentage ideal WFH chart (Percentage Ideal WFH chart, 1993, School Health Service, Ministry of Health, Singapore), which has been used as an acceptable measure of degree of childhood adiposity $(24,25)$.

Blood pressure. After at least $5 \mathrm{~min}$ of rest, blood pressure was measured twice using a mercury sphygmomanometer on the right arm of the seated participant, $15 \mathrm{~min}$ apart. The mean of two measurements (first phase Korotkoff systolic and fifth phase Korotkoff diastolic) was used for analysis.

Laboratory measurements. All blood samples were obtained at baseline and 5 y later. Fasting blood samples were taken and stored on ice until centrifugation. Plasma samples were stored at $-70^{\circ} \mathrm{C}$ for analysis in batches. Fasting plasma glucose and triglycerides (TG) were measured in the routine biochemistry laboratory (Hitachi 7170; Auto-Biochemistry Instruments). FI was measured by RIA (DSL). All the biochemistry assays were performed in China-Japan Friendship Hospital in Beijing, China. Insulin resistance was calculated using the homeostasis model assessment for insulin resistance (HOMA-IR) (26)

Statistical analysis. Statistical analysis was performed using SAS software 9.1 (SAS Institute, Cary, NC). Mean values and standard errors were calculated for all variables. WFH at recruitment at $5 \mathrm{y}$ old (WFH5), WFH at $10 \mathrm{y}$ old (WFH10), and the change in WFH from 5 to $10 \mathrm{y}$ old $(\Delta \mathrm{WFH})$ were obtained from local standard charts for Singapore Chinese children. The children were ranked in ascending order based on WFH5 and divided into tertiles. The process was repeated for $\triangle \mathrm{WFH}$. General linear model (GLM) of least squares means was used to determine association among variables. Linear trend and quadratic trend in the changes between tertiles were exam- ined using GLM. $t$ test was used to compare the difference between variables in boys and girls. Stepwise regression models were used to determine predictive factors of WFH5 and WFH10. In one regression model, with WFH5 as the dependent variable, gender, birth weight, and TV watching time were the independent variables. In the second regression model, where WFH10 was the dependent variable, gender, birth weight, TV watching time, and WFH5 were the independent variables.

\section{RESULTS}

Table 1 shows the clinical and laboratory measurements for the 424 children at $5 \mathrm{y}$ old divided into the percentage of ideal WFH tertiles. With increasing WFH5, statistically significant associations were present for birth weight in both genders. The association of increasing FI with increasing WFH5 was also statistically significant, as may be expected. However, there was no statistically significant association of blood pressure or fasting TG with increasing WFH5. Table 1 also shows that there was a gender difference in the association with FI; the mean FI in girls was higher than in each of the corresponding tertiles compared with boys, despite the greater body weight and height in boys. The increase in FI across the three WFH5 tertiles was greater in boys compared with girls. The reason for this gender difference is uncertain. There was a statistically significant association of TV viewing time with increase for WFH5 for boys, but the association in girls did not reach statistical significance.

Table 2 shows the clinical and laboratory measurements for the same cohort of 424 children at $10 \mathrm{y}$ old, after an interval of $5 \mathrm{y}$, based on the WFH5 (as in Table 1). This table allows us to see the longitudinal changes in the original WFH5 tertiles. We note several significant observations over the $5 \mathrm{y}$. Children who were initially of greater WFH and greater weight remained so after $5 \mathrm{y}$, and these were now associated with changes in blood pressure and FI (in boys). The differences in weight between the three tertiles within each gender had become greater after $5 \mathrm{y}$. However, there was still no statistically significant difference in the height or fasting TG between the tertiles at $10 \mathrm{y}$ old, compared with when the subjects were 5 y old.

Table 1. Clinical and laboratory data at entry of the follow-up in WFH Tertiles at baseline

\begin{tabular}{|c|c|c|c|c|c|c|}
\hline & \multicolumn{3}{|c|}{ Male (WFH5, \%) } & \multicolumn{3}{|c|}{ Female (WFH5, \%) } \\
\hline & Lowest tertile & Mid tertile & Highest tertile & Lowest tertile & Mid tertile & Highest tertile \\
\hline Variable & $90.77 \pm 3.95$ & $100.01 \pm 2.25$ & $116.81 \pm 12.48$ & $92.34 \pm 4.30$ & $100.62 \pm 2.23$ & $114.38 \pm 9.11$ \\
\hline No. & 71 & 69 & 71 & 71 & 71 & 71 \\
\hline Age (y) & $5.49 \pm 0.07$ & $5.57 \pm 0.07$ & $5.49 \pm 0.07$ & $5.39 \pm 0.07$ & $5.42 \pm 0.07$ & $5.35 \pm 0.07$ \\
\hline Height $(\mathrm{cm})$ & $122.13 \pm 0.55$ & $120.57 \pm 0.55$ & $121.24 \pm 0.55$ & $119.13 \pm 0.59$ & $118.88 \pm 0.59$ & $119.30 \pm 0.59$ \\
\hline Weight $(\mathrm{kg})$ & $21.04 \pm 0.39$ & $22.41 \pm 0.39 *$ & $26.65 \pm 0.39 \dagger \ddagger$ & $19.44 \pm 0.35$ & $21.04 \pm 0.35 \dagger$ & $24.22 \pm 0.35 \dagger$ \\
\hline Birth weight $(\mathrm{kg})$ & $3.33 \pm 0.05$ & $3.38 \pm 0.05$ & $3.54 \pm 0.05 \dagger+$ & $3.21 \pm 0.05$ & $3.40 \pm 0.05^{*}$ & $3.38 \pm 0.05^{*} \S$ \\
\hline $\mathrm{SBP}(\mathrm{mm} \mathrm{Hg})$ & $100.97 \pm 1.45$ & $101.51 \pm 1.47$ & $102.39 \pm 1.45$ & $98.65 \pm 1.45$ & $99.15 \pm 1.45$ & $102.34 \pm 1.45$ \\
\hline DBP (mm Hg) & $67.62 \pm 1.25$ & $66.35 \pm 1.27$ & $65.92 \pm 1.25$ & $66.14 \pm 1.32$ & $65.62 \pm 1.32$ & $66.37 \pm 1.32$ \\
\hline FI $(\mu / \mathrm{ml})$ & $3.69 \pm 0.37$ & $4.02 \pm 0.37$ & $5.29 \pm 0.37 \dagger+$ & $4.56 \pm 0.46$ & $4.70 \pm 0.46$ & $5.94 \pm 0.46 * \S$ \\
\hline HOMA-IR & $0.88 \pm 0.09$ & $0.96 \pm 0.09$ & $1.26 \pm 0.09 \dagger+$ & $1.06 \pm 0.11$ & $1.07 \pm 0.11$ & $1.39 \pm 0.11 * \S$ \\
\hline $\mathrm{TG}(\mathrm{mmol} / \mathrm{L})$ & $0.46 \pm 0.05$ & $0.57 \pm 0.06$ & $0.54 \pm 0.05$ & $0.57 \pm 0.08$ & $0.56 \pm 0.08$ & $0.75 \pm 0.08$ \\
\hline TV viewing time (h/wk) & $4.41 \pm 0.28$ & $4.70 \pm 0.29$ & $5.23 \pm 0.28 * \S$ & $4.59 \pm 0.29$ & $4.37 \pm 0.29$ & $5.28 \pm 0.29$ \\
\hline
\end{tabular}

All data were presented as mean \pm SE.

$* p<0.05$ (compared with group 1).

$\dagger p<0.01$ (compared with group 1).

$\$ p<0.01$ (three groups linear trend).

$\S p<0.05$ (three groups linear trend). 
Table 2. Clinical and laboratory data at the end of 5-y follow-up, where subjects are still grouped in WFH tertiles at baseline (5 y of age)

\begin{tabular}{|c|c|c|c|c|c|c|}
\hline & \multicolumn{3}{|c|}{ Male (WFH5, \%) } & \multicolumn{3}{|c|}{ Female (WFH5, \%) } \\
\hline & Lowest tertile & Mid tertile & Highest tertile & Lowest tertile & Mid tertile & Highest tertile \\
\hline Variable & $90.77 \pm 3.95$ & $100.01 \pm 2.25$ & $116.81 \pm 12.48$ & $92.34 \pm 4.30$ & $100.62 \pm 2.23$ & $114.38 \pm 9.11$ \\
\hline No. & 71 & 69 & 71 & 71 & 71 & 71 \\
\hline Age (y) & $10.49 \pm 0.07$ & $10.57 \pm 0.07$ & $10.49 \pm 0.07$ & $10.39 \pm 0.07$ & $10.42 \pm 0.07$ & $10.34 \pm 0.07$ \\
\hline Height $(\mathrm{cm})$ & $143.51 \pm 0.68$ & $142.35 \pm 0.69$ & $143.28 \pm 0.68$ & $140.99 \pm 0.79$ & $141.58 \pm 0.79$ & $142.95 \pm 0.79$ \\
\hline Weight (kg) & $33.70 \pm 0.90$ & $35.26 \pm 0.91$ & $44.29 \pm 0.90^{* \dagger}$ & $31.04 \pm 0.79$ & $33.20 \pm 0.79$ & $39.79 \pm 0.79 * \dagger$ \\
\hline WFH10 (\%) & $91.43 \pm 1.60$ & $97.56 \pm 1.63^{*}$ & $120.89 \pm 1.60^{* \dagger} \dagger$ & $91.05 \pm 1.33$ & $96.01 \pm 1.32 *$ & $111.00 \pm 1.32 * \dagger$ \\
\hline SBP (mm Hg) & $94.62 \pm 1.23$ & $95.16 \pm 1.25$ & $101.41 \pm 1.23^{*}$ & $93.44 \pm 0.89$ & $95.77 \pm 0.87$ & $98.65 \pm 0.89^{*}$ \\
\hline DBP (mm Hg) & $65.04 \pm 0.85$ & $64.23 \pm 0.87$ & $67.58 \pm 0.85 \ddagger$ & $63.46 \pm 0.88$ & $62.62 \pm 0.88$ & $65.07 \pm 0.88$ \\
\hline FI $(\mu / \mathrm{mL})$ & $3.97 \pm 0.35$ & $4.24 \pm 0.36$ & $5.28 \pm 0.35^{* \dagger}$ & $4.00 \pm 0.39$ & $4.11 \pm 0.39$ & $5.05 \pm 0.39$ \\
\hline HOMA-IR & $0.96 \pm 0.09$ & $1.06 \pm 0.09$ & $1.30 \pm 0.09 * \dagger$ & $1.03 \pm 0.10$ & $1.00 \pm 0.10$ & $1.23 \pm 0.10$ \\
\hline TG (mmol/L) & $0.95 \pm 0.05$ & $1.00 \pm 0.05$ & $1.06 \pm 0.05$ & $1.03 \pm 0.06$ & $1.04 \pm 0.06$ & $1.12 \pm 0.06$ \\
\hline
\end{tabular}

All data were presented as mean $\pm \mathrm{SE}$.

$* p<0.01$ (compared with group 1).

$\dagger p<0.01$ (three groups linear trend).

$\ddagger p<0.05$ (compared with group 1 ).

$\S p<0.05$ (three groups linear trend).

Table 3. Clinical and laboratory data at baseline according to WFH-change tertiles during the 5-y follow-up

\begin{tabular}{|c|c|c|c|c|c|c|}
\hline & \multicolumn{3}{|c|}{ Male } & \multicolumn{3}{|c|}{ Female } \\
\hline & Group 1 & Group 2 & Group 3 & Group 1 & Group 2 & Group 3 \\
\hline Variable & $-11.15 \pm 4.63$ & $-1.10 \pm 3.38$ & $14.66 \pm 7.40$ & $-12.41 \pm 4.51$ & $-4.53 \pm 1.88$ & $7.57 \pm 8.18$ \\
\hline No. & 70 & 71 & 70 & 71 & 71 & 71 \\
\hline Age (y) & $5.51 \pm 0.07$ & $5.49 \pm 0.07$ & $5.55 \pm 0.07$ & $5.37 \pm 0.07$ & $5.44 \pm 0.07$ & $5.35 \pm 0.07$ \\
\hline Height $(\mathrm{cm})$ & $120.45 \pm 0.54$ & $120.62 \pm 0.54$ & $122.90 \pm 0.54^{*}$ & $119.97 \pm 0.59$ & $118.18 \pm 0.58$ & $119.13 \pm 0.58$ \\
\hline Weight $(\mathrm{kg})$ & $23.07 \pm 0.48$ & $22.35 \pm 0.48$ & $24.72 \pm 0.48^{* \dagger}$ & $21.97 \pm 0.42$ & $20.53 \pm 0.42 \ddagger$ & $22.16 \pm 0.42 \S$ \\
\hline Birth weight $(\mathrm{kg})$ & $3.41 \pm 0.05$ & $3.42 \pm 0.05$ & $3.43 \pm 0.05$ & $3.42 \pm 0.05$ & $3.21 \pm 0.05$ & $3.36 \pm 0.05$ \\
\hline $\mathrm{SBP}(\mathrm{mm} \mathrm{Hg})$ & $101.40 \pm 1.46$ & $100.96 \pm 1.45$ & $102.53 \pm 1.46$ & $100.24 \pm 1.47$ & $98.83 \pm 1.46$ & $101.08 \pm 1.46$ \\
\hline $\mathrm{DBP}(\mathrm{mm} \mathrm{Hg})$ & $64.93 \pm 1.25$ & $66.68 \pm 1.24$ & $68.29 \pm 1.25$ & $66.44 \pm 1.33$ & $64.80 \pm 1.33$ & $66.83 \pm 1.33$ \\
\hline FI $(\mu / \mathrm{mL})$ & $4.16 \pm 0.38$ & $4.50 \pm 0.38$ & $4.35 \pm 0.38$ & $5.38 \pm 0.47$ & $4.62 \pm 0.46$ & $5.22 \pm 0.46$ \\
\hline HOMA-IR & $0.98 \pm 0.09$ & $1.08 \pm 0.09$ & $1.05 \pm 0.09$ & $1.24 \pm 0.11$ & $1.07 \pm 0.11$ & $1.21 \pm 0.11$ \\
\hline $\mathrm{TG}(\mathrm{mmol} / \mathrm{L})$ & $0.50 \pm 0.05$ & $0.48 \pm 0.05$ & $0.59 \pm 0.05$ & $0.62 \pm 0.08$ & $0.68 \pm 0.08$ & $0.58 \pm 0.08$ \\
\hline TV viewing time $(\mathrm{h} / \mathrm{wk})$ & $4.18 \pm 0.28$ & $4.83 \pm 0.28$ & $5.31 \pm 0.28 * \|$ & $4.41 \pm 0.29$ & $4.54 \pm 0.29$ & $5.31 \pm 0.29+\dagger$ \\
\hline
\end{tabular}

All data were means \pm SE.

$* p<0.01$ (compared with group 1).

$\dagger p<0.05$ (three groups linear trend).

$\$ p<0.05$ (compared with group 1).

$\S p<0.05$ (three groups quadratic trend).

$\| p<0.01$ (three groups linear trend).

There were some gender differences. Boys at the top tertile were $4.5 \mathrm{~kg}$ heavier than girls at the top tertile $(p=0.003)$, although the mean height was similar. In addition, the mean WFH of boys in the top WFH5 tertile was now $\sim 10 \%$ higher than that of the girls in top tertile $(p=0.0003)$, whereas the WFH10 of the two lower tertiles was similar. Although systolic blood pressure (SBP) was statistically significantly higher in the top tertile compared with the lowest tertiles in both boys and girls, the diastolic blood pressure (DBP) was significantly higher in the top tertile in the boys only. In boys, there was significant increase in FI and HOMA-IR across the tertiles, but in girls, this did not reach statistical significance.

To further explore the possible predictors of adiposity (as assessed by WFH) and characteristics associated with the metabolic syndrome, we analyzed the relationship between the basal measurements at $5 \mathrm{y}$ according to tertiles of the longitudinal change in WHF over the $5 \mathrm{y}(\Delta \mathrm{WFH})$. Table 3 depicts the baseline measurements at $5 \mathrm{y}$ old (baseline) when the cohort was divided into tertiles according to $\triangle \mathrm{WFH}$ over the $5 \mathrm{y}$ of follow-up. In boys, the height and weight incremental trend across the tertiles suggests that greater height and weight at $5 \mathrm{y}$ old may be significant predictors of greater increase in adiposity later, in our case, by $10 \mathrm{y}$ old. The trend appears to be more important for boys than for girls. TV viewing time was statistically significantly different between the top $\triangle \mathrm{WFH}$ tertile and the lowest tertile in both genders (boys: $5.31 \pm 0.28$ versus $4.18 \pm 0.28, p<0.01$; girls: $5.31 \pm 0.29$ versus $4.41 \pm 0.29, p<0.05, \mathrm{~h} / \mathrm{wk}$ ), and coupled with the statistically significant linear trend across the three groups, this is consistent for both boys and girls. There was a strong association between change in WFH over $5 \mathrm{y}$ and TV viewing time, which is more marked in boys than girls (Fig. $1 A$ and $B$ ). Importantly and perhaps surprisingly, birth weight, HOMAIR, FI, and other parameters at baseline were not significantly associated with $\triangle \mathrm{WFH}$ tertiles for either gender group, as shown in Table 3 . The only significant predictor was TV viewing time. 
Similarly, in Table 4, we analyzed the associations of the measurements at $10 \mathrm{y}$ old with the tertiles of $\Delta \mathrm{WFH}$ over the $5 \mathrm{y}$. These supported our finding that $\Delta \mathrm{WFH}$ predicted risk factors for development of changes of the metabolic syndrome at 10 y old: weight, FI, HOMA-IR index, SBP, DBP, and TG. All these variables were significantly worse in the top tertile group compared with the lowest tertile. This also showed a significant linear or quadratic trend across the tertiles, for both boys and girls. An interesting observation was that the boys in the top tertile (with positive $\Delta \mathrm{WFH}$ ) were taller than the boys of lower tertiles (with negative $\Delta \mathrm{WFH})(145.03 \pm 0.67$ versus
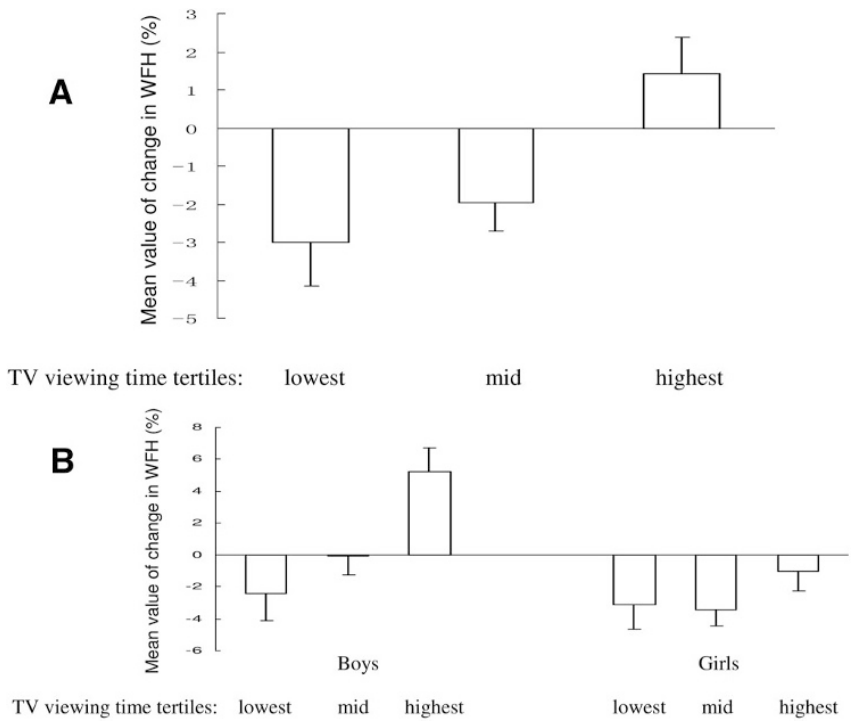

Figure 1. (A) Change in WFH from 5 to $10 \mathrm{y}$ of age according to TV viewing time tertiles. The mean values of change in WFH from 5 to $10 \mathrm{y}$ old in the top tertile were significantly greater than the lowest tertile $(p=0.0003)$. $(B)$ Change in WFH from 5 to $10 \mathrm{y}$ old according to TV viewing time tertiles by gender. The change in WFH from 5 to $10 \mathrm{y}$ old in the top tertile was significantly greater than the lowest tertile $(p=0.002)$ in boys but did not reach statistical significance in girls. TV viewing time of all subjects (h/wk): lowest tertile: $2.27 \pm 0.70$; mid tertile: $4.29 \pm 0.45$; highest tertile: $7.35 \pm 2.70$. For boys $(\mathrm{h} / \mathrm{wk})$ : lowest tertile: $2.34 \pm 0.56$; mid tertile: $4.29 \pm 0.45$; highest tertile: $7.54 \pm 2.51$. For girls (h/wk): lowest tertile: $2.19 \pm 0.83$; mid tertile: $4.30 \pm 0.46$; highest tertile: $7.17 \pm 2.88$ (data presented as mean $\pm \mathrm{SE}$ ).
$142.20 \pm 0.67, \mathrm{~cm}, p<0.01$ ), despite the higher WFH. This implied there was increase not only in adiposity but also in linear growth. There was no significant difference in girls. Boys in the top tertile (and positive $\Delta \mathrm{WFH}$ ) were taller ( $p=$ $0.006)$, with higher SBP $(p=0.056)$ and DBP $(p=0.009)$ than girls in the top tertile (positive $\Delta \mathrm{WFH}$; Table 4).

We performed further analysis of the measurements to distinguish the relative contributions of birth weight and TV viewing time on WFH at $5 \mathrm{y}$ and $10 \mathrm{y}$. Using multiple stepwise analysis with WFH5 as dependent variable, birth weight and TV viewing time as independent variables (Table 5, model 1), both birth weight and TV viewing time were significantly correlated with WFH5 (birth weight: $p=0.0032$; TV viewing time: $p=0.01$. Gender did not enter the model at $p>0.15$ level). When we used multiple stepwise analysis with WFH10 as the dependent variable, and birth weight and TV viewing time as independent variables, only TV viewing time was significantly correlated with WFH10 after adjustment for gender $(p<0.0001$; Table 5, model $2)$. The correlation between birth weight and WFH10 was not statistically significant $(p=0.06)$. TV viewing time had a stronger effect on WFH10 than WFH5 ( $\beta /$ SE: 4.56 versus 2.58 ). As WFH5 correlated significantly with WFH10 (Pearson correlation coefficient $0.7402, p<0.0001$ ), by including WFH5 as an independent variable into above model, birth weight was re-

Table 5. Relationship between WFH, TV viewing time, and birth weight

\begin{tabular}{lllc}
\hline Independent variable & $\beta$ & SE & $p$ \\
\hline Model 1: at 5 y of age & & & \\
Birth weight (kg) & 0.004 & 0.001 & 0.0032 \\
TV viewing time (h/wk) & 0.62 & 0.24 & 0.01 \\
Model 2: at 10 y of age & & & \\
Gender (boy = 1, girls =2) & -4.25 & 1.57 & 0.004 \\
Birth weight (kg) & 0.003 & 0.002 & 0.06 \\
TV viewing time (h/wk) & 1.46 & 0.32 & $<0.0001$ \\
Model 3: at 10 y of age & & & \\
Gender (boy = 1, girls = 2) & -3.88 & 1.05 & 0.0002 \\
TV viewing time (h/wk) & 0.86 & 0.22 & $<0.0001$ \\
WFH at 5 y (\%) & 0.99 & 0.04 & $<0.0001$ \\
\hline
\end{tabular}

Model 1: WFH at 5 y of age as dependent variable; models 2 and 3: WFH at $10 \mathrm{y}$ of age as dependent variable.

Table 4. Clinical and laboratory data at the end of 5-y follow-up in WFH-change tertiles during the 5-y follow-up

\begin{tabular}{|c|c|c|c|c|c|c|}
\hline & \multicolumn{3}{|c|}{ Male } & \multicolumn{3}{|c|}{ Female } \\
\hline & Group 1 & Group 2 & Group 3 & Group 1 & Group 2 & Group 3 \\
\hline Variable & $-11.15 \pm 4.63$ & $-1.10 \pm 3.38$ & $14.66 \pm 7.40$ & $-12.41 \pm 4.51$ & $-4.53 \pm 1.88$ & $7.57 \pm 8.18$ \\
\hline Age (y) & $10.51 \pm 0.07$ & $10.49 \pm 0.07$ & $10.55 \pm 0.07$ & $10.38 \pm 0.07$ & $10.44 \pm 0.07$ & $10.35 \pm 0.07$ \\
\hline Height $(\mathrm{cm})$ & $142.20 \pm 0.67$ & $141.94 \pm 0.07$ & $145.03 \pm 0.67^{*}$ & $143.33 \pm 0.79$ & $140.52 \pm 0.78$ & $141.67 \pm 0.78$ \\
\hline Weight (kg) & $32.99 \pm 0.85$ & $35.17 \pm 0.85$ & $45.19 \pm 0.85^{* \dagger}$ & $32.61 \pm 0.83$ & $32.39 \pm 0.82$ & $39.08 \pm 0.82 * \dagger$ \\
\hline FI $(\mu / \mathrm{mL})$ & $3.86 \pm 0.35$ & $4.17 \pm 0.35$ & $5.47 \pm 0.35^{* \dagger}$ & $3.69 \pm 0.38$ & $3.87 \pm 0.38$ & $5.64 \pm 0.38^{* \dagger}$ \\
\hline HOMA-IR & $0.94 \pm 0.09$ & $1.03 \pm 0.09$ & $1.35 \pm 0.09 * \S$ & $0.88 \pm 0.09$ & $0.94 \pm 0.09$ & $1.38 \pm 0.09^{*} \dagger$ \\
\hline $\mathrm{TG}(\mathrm{mmol} / \mathrm{L})$ & $0.91 \pm 0.05$ & $0.97 \pm 0.05$ & $1.14 \pm 0.05^{* \dagger}$ & $0.98 \pm 0.06$ & $1.02 \pm 0.06$ & $1.19 \pm 0.06 \div \S$ \\
\hline
\end{tabular}

All data were presented as mean $\pm \mathrm{SE}$.

$* p<0.01$ (compared with group 1).

$\dagger p<0.01$ (three groups linear trend).

$\$ p<0.05$ (compared with group 1 ).

$\S p<0.05$ (three groups linear trend).

$\| p<0.05$ (three groups linear trend). 
moved from the model, and both WFH5 and TV viewing time were significantly correlated with WFH10 $(p<0.0001$; Table 5 , model 3).

\section{DISCUSSION}

Childhood adiposity is complex and multifactorial, determined by genetic factors, in utero and early life developmental programming, and subsequent environmental influences. Our study found both TV viewing time and birth weight affected adiposity during early childhood at $5 \mathrm{y}$ old, and early childhood adiposity ( $5 \mathrm{y}$ old) and TV time at that age predicts later childhood adiposity ( $10 \mathrm{y}$ old). Although birth weight predicts adiposity at $5 \mathrm{y}$ old, its influence appeared to be wane in late childhood, as demonstrated in our stepwise regression analyses (Table 5). By contrast, TV viewing time has a greater effect on WFH at $10 \mathrm{y}$ old than WFH at $5 \mathrm{y}$ old, and significantly, with the increase in WFH from early to late childhood (5 to $10 \mathrm{y}$ old). This association remained significant after adjusting for family income. Every child spent some time watching TV every week. Nearly $90 \%$ children spent 2 to $6 \mathrm{~h} / \mathrm{wk}$ watching TV, and the mode was $4 \mathrm{~h} / \mathrm{wk}$ (35\% of the children). There was no correlation between family income and TV viewing time. Unfortunately, information on other potential confounders like parental BMI were not collected for further adjustment. Nonetheless, the strong association is likely to reflect a causal relationship between TV viewing and increase in adiposity. Our results showed that an increase of 5 $\mathrm{h} / \mathrm{wk}$ of TV viewing time is associated with an increase of WFH by $\sim 5 \%$ from 5 to $10 \mathrm{y}$ old (Fig. $1 A$ ). If birth weight is primarily a result of genetic and in utero developmental factors, and TV viewing time represents the extent of sedentary behavior in a modern day environment, our findings would then support the notion that behavioral or environment factors may be stronger determinants of adiposity in later childhood compared with the genetic and epigenetic (developmental) factors, which may have a more significant influence on early childhood adiposity.

Our study also suggested that there may be a gender difference in the effect of TV viewing time on adiposity, where the boys appeared to be more susceptible, not only at $5 \mathrm{y}$ old but also had greater increase in adiposity from 5 to $10 \mathrm{y}$ old (Tables 1 and 3; Fig. 1B). The reason for this gender difference is unknown, and we can speculate that young Chinese girls may be more likely to have other sedentary activities such as reading and quiet play, and thus the effects of TV viewing is somewhat diluted. Chinese girls may also help to perform housework regularly which is a form of physical activity too.

Several studies support our finding of the relationship of TV viewing time to obesity and weight gain of children in various populations $(20,21,27,28)$. Findings of another follow-up study of 3 y old of children was consistent with our results, which concluded that 6 to $7 \mathrm{y}$ is a critical age when TV viewing and physical activity might affect BMI (29). Although we did not measure physical inactivity in this study, we used TV viewing time as a surrogate marker. TV viewing time is assumed to reflect sedentary lifestyle or behavior which deprives a child of physical activity. However, the relationship between TV viewing and excessive weight gain may not be simply due to reduced energy expenditure alone (30). TV viewing may often be accompanied by increased consumption of high calorie foods, with high sugar or high fat content, and sweetened drinks. The child may also be influenced by exposure to unhealthy TV advertisements on fast foods, snacks, candies, and soft drinks $(31,32)$, and their food choice may be affected (33).

Our study showed that TV viewing time in Chinese schoolaged children is relatively short compared with reports from Western countries, as Chinese students usually have large quantities of homework. School hours are usually long, from $8 \mathrm{am}$ to $4 \mathrm{pm}$ on weekdays. A Chinese study showed that $41.8 \%$ of junior high school children spent $<0.5 \mathrm{~h}$ on average viewing TV each day, and only $20 \%$ of students spent $>1$ h on viewing TV (34). Bearing in mind that our study subjects were in the elementary school, we postulate that the children probably would not continue to have such long TV viewing time when they enter high school, and yet, the effect of TV viewing during early childhood at $5 \mathrm{y}$ old or earlier still had a profound effect on adiposity gain later in childhood.

As expected, children with greater WFH5 had relatively higher FI levels and HOMA-IR index. We observed a gender difference in FI levels; the gradient of increase in FI across the range of WFH was more pronounced in boys than girls. Boys appear to have greater variance in insulin resistance indices. Girls in early childhood appeared to have higher insulin resistance than boys, but the gap seemed to close in later childhood. The boys, but not the girls, showed a significant correlation between FI level and HOMA-IR at $10 \mathrm{y}$ old with WFH5. This may suggest that boys are more susceptive to developing insulin resistance in response to increasing WFH even at $5 \mathrm{y}$ old.

Our findings support the notion that rate of change in childhood adiposity can predict metabolic health status $(11,35)$, where higher or positive $\Delta \mathrm{WFH}$ may confer risk of development of components of metabolic syndrome. At $10 \mathrm{y}$ old, the children in the top and (the only) positive $\Delta \mathrm{WFH}$ tertile, which represented excess weight gain from 5 to $10 \mathrm{y}$ old, had significantly higher values of cardiovascular risk factors (FI, HOMA-IR, SBP, DBP, and TG) compared with the lower or (the two) negative $\Delta \mathrm{WFH}$ tertiles, bearing in mind that there was not as a statistically significant difference in these measurements across the WFH5 tertiles. Consistent with our results, a recent study of 233 children followed up for $9 \mathrm{y}$ from birth also found that overweight or obese children at 9 y old had higher levels of HOMA-IR, TG, and mean blood pressure, and weight gain from 5 to $9 \mathrm{y}$ predicted their metabolic risk (36).

In summary, TV viewing time during early childhood was a better predictor of adiposity at late childhood (10 y old) compared with birth weight. WFH5 predicted WFH10 and also metabolic factors which confer cardiovascular risk. Adiposity gain from 5 to $10 \mathrm{y}$ old also significantly predict this risk. Thus, reducing TV viewing time among young children at early age may help to prevent subsequent development of obesity and the accumulate risk of metabolic syndrome. 


\section{REFERENCES}

1. National Task Force on Childhood Obesity, National Center for Women's and Children's Health; Ding ZY 2008 [National epidemiological survey on childhood obesity, 2006]. Zhonghua Er Ke Za Zhi 46:179-184

2. Maffeis C, Moghetti P, Grezzani A, Clementi M, Gaudino R, Tato L 2002 Insulin resistance and the persistence of obesity from childhood into adulthood. J Clin Endocrinol Metab 87:71-76

3. Goran MI, Ball GD, Cruz ML 2003 Obesity and risk of type 2 diabetes and cardiovascular disease in children and adolescents. J Clin Endocrinol Metab $88: 1417-1427$

4. Sorof J, Daniels S 2002 Obesity hypertension in children: a problem of epidemic proportions. Hypertension 40:441-447

5. Lammi N, Moltchanova E, Blomstedt PA, Tuomilehto J, Eriksson JG, Karvonen M 2009 Childhood BMI trajectories and the risk of developing young adult-onset diabetes. Diabetologia 52:408-414

6. Al Mamun A, Cramb SM, O'Callaghan MJ, Williams GM, Najman JM 2009 Childhood overweight status predicts diabetes at age 21 years: a follow-up study. Obesity (Silver Spring) 17:1255-1261

7. Klumbiene J, Sileikiene L, Milasauskiene Z, Zaborskis A, Shatchkute A 2000 The relationship of childhood to adult blood pressure: longitudinal study of juvenile hypertension in Lithuania. J Hypertens 18:531-538

8. Bao W, Threefoot SA, Srinivasan SR, Berenson GS 1995 Essential hypertension predicted by tracking of elevated blood pressure from childhood to adulthood: the Bogalusa Heart Study. Am J Hypertens 8:657-665

9. Kindblom JM, Lorentzon M, Hellqvist A, Lonn L, Brandberg J, Nilsson S, Norjavaara E, Ohlsson C 2009 BMI changes during childhood and adolescence as predictors of amount adult subcutaneous and visceral adipose tissue in men-the GOOD Study. Diabetes 58:867-874

10. Mattsson N, Ronnemaa T, Juonala M, Viikari JS, Raitakari OT 2008 Childhood predictors of the metabolic syndrome in adulthood. The Cardiovascular Risk in Young Finns Study. Ann Med 40:542-552

11. Baker JL, Olsen LW, Sorensen TI 2007 Childhood body-mass index and the risk of coronary heart disease in adulthood. N Engl J Med 357:2329-2337

12. Srinivasan SR, Myers L, Berenson GS 2002 Predictability of childhood adiposity and insulin for developing insulin resistance syndrome (syndrome $\mathrm{X}$ ) in young adulthood: the Bogalusa Heart Study. Diabetes 51:204-209

13. Hui LL, Schooling CM, Leung SS, Mak KH, Ho LM, Lam TH, Leung GM 2008 Birth weight, infant growth, and childhood body mass index: Hong Kong's children of 1997 birth cohort. Arch Pediatr Adolesc Med 162:212-218

14. Buyken AE, Karaolis-Danckert N, Remer T, Bolzenius K, Landsberg B, Kroke A 2008 Effects of breastfeeding on trajectories of body fat and BMI throughout childhood. Obesity (Silver Spring) 16:389-395

15. Wells JC 2007 The programming effects of early growth. Early Hum Dev 83:743748

16. Seidman DS, Laor A, Gale R, Stevenson DK, Danon YL 1991 A longitudinal study of birth weight and being overweight in late adolescence. Am J Dis Child 145:782785

17. Dubois L, Girard M 2006 Early determinants of overweight at 4.5 years in a population-based longitudinal study. Int J Obes (Lond) 30:610-617

18. Must A, Tybor DJ 2005 Physical activity and sedentary behavior: a review of longitudinal studies of weight and adiposity in youth. Int J Obes (Lond) 29:S84-S96
19. Swinburn B, Shelly A 2008 Effects of TV time and other sedentary pursuits. Int J Obes (Lond) 32:S132-S136

20. Dietz WH Jr, Gortmaker SL 1985 Do we fatten our children at the television set? Obesity and television viewing in children and adolescents. Pediatrics 75:807-812

21. Gortmaker SL, Must A, Sobol AM, Peterson K, Colditz GA, Dietz WH 1996 Television viewing as a cause of increasing obesity among children in the United States, 1986-1990. Arch Pediatr Adolesc Med 150:356-362

22. Salmon J, Bauman A, Crawford D, Timperio A, Owen N 2000 The association between television viewing and overweight among Australian adults participating in varying levels of leisure-time physical activity. Int J Obes Relat Metab Disord 24:600-606

23. Bowman SA 2006 Television-viewing characteristics of adults: correlations to eating practices and overweight and health status. Prev Chronic Dis 3:A38

24. Mei Z, Grummer-Strawn LM, Pietrobelli A, Goulding A, Goran MI, Dietz WH 2002 Validity of body mass index compared with other body-composition screening indexes for the assessment of body fatness in children and adolescents. Am J Clin Nutr 75:978-985

25. Alemzadeh R, Lifshitz F 1996 Childhood obesity. In: Lifshitz F (ed) Pediatric Endocrinology. Marcel Dekker, New York, NY, pp 753-774

26. Matthews DR, Hosker JP, Rudenski AS, Naylor BA, Treacher DF, Turner RC 1985 Homeostasis model assessment: insulin resistance and beta-cell function from fasting plasma glucose and insulin concentrations in man. Diabetologia 28:412-419

27. Hernández B, Gortmaker SL, Colditz GA, Peterson KE, Laird NM, Parra-Cabrera S 1999 Association of obesity with physical activity, television programs and other forms of video viewing among children in Mexico City. Int J Obes Relat Metab Disord 23:845-854

28. Anastassea-Vlachou K, Fryssira-Kanioura H, Papathanasiou-Klontza D, XipolitaZachariadi A, Matsaniotis N 1996 The effects of television viewing in Greece, and the role of the paediatrician: a familiar triangle revisited. Eur J Pediatr 155:10571060

29. Jago R, Baranowski T, Baranowski JC, Thompson D, Greaves KA 2005 BMI from $3-6$ y of age is predicted by TV viewing and physical activity, not diet. Int J Obes (Lond) 29:557-564

30. Marshall SJ, Biddle SJ, Gorely T, Cameron N, Murdey I 2004 Relationships between media use, body fatness and physical activity in children and youth: a meta-analysis. Int J Obes Relat Metab Disord 28:1238-1246

31. Powell LM, Szczypka G, Chaloupka FJ 2007 Exposure to food advertising on television among US children. Arch Pediatr Adolesc Med 161:553-560

32. Powell LM, Szczypka G, Chaloupka FJ, Braunschweig CL 2007 Nutritional content of television food advertisements seen by children and adolescents in the United States. Pediatrics 120:576-583

33. Christakis DA 2006 The hidden and potent effects of television advertising. JAMA 295:1698-1699

34. Shi Z, Lien N, Kumar BN, Holmboe-Ottesen G 2006 Physical activity and associated socio-demographic factors among school adolescents in Jiangsu Province, China. Prev Med 43:218-221

35. Freedman DS, Mei Z, Srinivasan SR, Berenson GS, Dietz WH 2007 Cardiovascular risk factors and excess adiposity among overweight children and adolescents: the Bogalusa Heart Study. J Pediatr 150:12.e2-17.e2

36. Gardner DS, Hosking J, Metcalf BS, Jeffery AN, Voss LD, Wilkin TJ 2009 Contribution of early weight gain to childhood overweight and metabolic health: a longitudinal study (EarlyBird 36). Pediatrics 123:e67-e73 